record these very dramatic facts for himself, and Sir Stanton said that one of the major difficulties in running the class was to get the students out of the laboratory in time to have it cleaned up for the next day.

\section{The Student's Problem}

Education is essentially a partnership, and having considered the teacher's side we must not forget the student. The student of to-day faces a problem that is in many ways much grimmer than that which faced his predecessors. Often he is dependent on a grant which continues only so long as he passes his examinations. The exigencies of war and the pressure of students on medical schools have led to the practice of expelling a student after one or two failures in an examination. The student's request is accordingly a simple one: he asks to be put through his examinations. Whether or not he is educated in the process is to him a secondary consideration.

If we teachers place a high value on education, and on method, we must ensure that the student who has acquired this is duly rewarded. This can be done in two ways: by taking into account his performance in class during the year, and by ensuring that the examination is largely a test of method. For I doubt whether we are in a position to do away with examinations. Nevertheless, they require the same careful study as-the course itself. If the course is being designed to impart method the examinations must be designed to test how far method has been acquired. And since all professional examinations have and must continue to have an external examiner, it is clear that he also must understand and be in sympathy with what has been attempted. His selection therefore requires equal care.

The reader who has persisted thus far may remark that this article is just loose talk, that the writer has not laid down a precise syllabus, that he has not told the physiologist what he must teach and what he need not, and that he has not laid down the number of hours to be devoted to lectures and tutorials and practical classes. I have not done this, for three reasons: first, because I was not competent to do so ; secondly, because I profoundly distrust any precise statements on matters that are so controversial ; but my chief reason is that these matters are of less importance than the attitude of mind of the teacher and the student. I personally do not mind if a student comes to me in medicine with enormous lacunae in his knowledge ; these he can very quickly repair once they are pointed out to him, if he has learned how to learn. But I do very strongly object when I meet students who have already had three years of university education, and who, far from having the scientific attitude of mind, have not the least idea what the scientific method is. That $I$ regard as the most heinous crime of our system of medical education to-day.

REFERENCES

Cambridge University Appointments Board (1945). "University Education and Business."

Lewis, T. (1945). Exercises in Human Physiology. London.

Pearson, Karl (1900). The Grammar of Science. 2nd ed. London.

Royal College of Physicians Planning Committee (1944). Report on Medical Education. London.

" It could be said, I suppose, that of all the changes which have occurred in the last half-century, the most beneficent are the discoveries of medical science. Assuredly much pain has been alleviated and much hope created by contemporary researches into the functioning of the endocrine glands and by such discoveries as insulin and the many varieties of antiseptic and anaesthetic drugs."-Mr. Harold Nicolson, the Spectator, August 19, 1949.

\section{THE TEACHING OF CHEMISTRY}

BY

E. C. DODDS, M.V.O., M.D., F.R.C.P., F.R.S. Courtauld Professor of Biochemistry, University of London

The teaching of chemistry to medical students has been one of the most controversial subjects in the whole of medical education. That a sound knowledge of organic and physical chemistry is necessary for the proper understanding of medical and allied subjects will be disputed by nobody; but what is the best method of imparting this knowledge ? Medical students are taught chemistry usually in one of two ways. If they are students at a university possessing a single chemistry department, they attend special courses in this department. On the other hand, if they are students at a medical school attached to one of the big London teaching hospitals, the medical school in most instances provides teaching of the complete curriculum and the student is taught chemistry in the chemical department of the medical school.

\section{Two Methods}

It must be emphasized at the outset that these instances differ entirely in the problem they present. A university chemical department is naturally a highly specialized and well-equipped institution with a series of professors for organic chemistry, inorganic chemistry, physical chemistry, and so forth. Each of these subdepartments of chemistry is fitted with modern apparatus and well-turned-out teaching laboratories. Here are all the facilities for teaching, together with the necessary inspiration and drive given to a subject by those engaged in original research. Theoretically at least, in these circumstances the medical student should have the advantage of an ideal education in chemistry.

Before considering in detail what happens to him in this department, let us turn to the potentialities for the student in the hospital medical school. From the material point of view he is obviously very much worse off than his fellow-student at a university chemical department; for medical schools cannot afford to maintain and equip a chemical department of the same standing as that in a university. They obviously cannot afford to have three or four professors for the teaching of the various branches of chemistry, nor have they the space for separate departments of inorganic, organic, and physical chemistry. Again, the equipping of laboratories of this type with modern apparatus would be an expense beyond their power. The chemistry department is therefore organized on different lines, consistent with its admittedly more limited scope. One man is responsible for organizing the teaching in all branches of chemistry, and he is assisted by more junior lecturers and demonstrators. The teacher of chemistry in the hospital medical school can claim an advantage over his counterpart in the university chemical department. Having spent years in a medical school, he has become acquainted with the ways and minds of medical students and is therefore perhaps in a better position than others to have responsibility for their chemical instruction. We can quote many examples of distinguished organic chemists who have devoted the greater part of their lives to the teaching of medical students.

To switch back to the university chemical department, one must point out that the position of such a student is not quite so enviable as would appear at first sight. For a number of years past every university chemical department in the country has been grossly overcrowded 
with honours and ordinary-degree students taking chemistry in its various branches as their main subject. Laboratory accommodation for practical work in every university in the country is inadequate, and almost without exception practical classes have to be run in shifts. The director of a university chemical department would indeed be abnormal if he did not regard the purely chemical student as his first charge, and not unnaturally the medical students are regarded as an unfortunate burden and necessity. They have to be fitted in to suit the convenience of the degree students, and usually the less senior and inspiring teachers are allotted for their instruction. We can sympathize with the purely chemical teacher in the university chemical department, to whom by definition the medical student must be little other than a nuisance.

\section{Value of Chemistry to the Medical Student}

It is very difficult for the medical student to -regard the instruction for the first and second medical examinations as other than hurdles and obstacles put in his path to prevent his getting to the clinical work in the hospital. Chemistry to him means a kind of barbed-wire entanglement through which he must cut his way and so get to the patients in the wards. Unless he is very carefully taught, he does not realize that chemistry is being taught him for its intrinsic value, nor how it will help him when he does get to the wards. The teacher in the university chemical department completely loses sight of the medical student as soon as he has passed his second M.B., and one can well understand the lack of interest which must inevitably arise in these teachers.

We are faced, therefore, with an unsatisfactory state of affairs both in the university chemical department and in the hospital medical school. In order to solve this difficult problem we must first of all try to define how much chemical knowledge is necessary for the efficient practice of medicine. This is said advisedly, since we must never lose sight of the fact that the main function of the medical schools is to produce practising doctors and not medical research workers. Every commission and committee that has sat on the revision of the medical curriculum has had ponderous and far-reaching comments to make about the teaching of chemistry, but it is my opinion that very few people who have studied this problem really see it in its proper perspective.

Obviously the ideal form of education would be to give the medical student a competent working knowledge of organic chemistry and biochemistry. To do this would take several years of study of chemistry and later of biochemistry alone. It is obvious that such a course is impossible, and we are therefore faced with the limiting factor of how much knowledge can be imparted to the average student in the six or seven years during which he is available for tuition at the medical school. The amount of time allotted for the teaching of chemistry and biochemistry has been settled as a result of uneasy compromise between the warring factions of anatomy, physiology, and chemistry. The only practical way to regard the problem is to accept with as good a grace as possible this allocation of time and to see what can be fitted into it.

\section{Co-ordination of Work}

We may assume that the student of to-day, and certainly of the future, will come to the medical school with a fairly competent knowledge of elementary inorganic and physical chemistry, and either a smattering of organic chemistry or none at all. It would seem to me that the first and most important consideration is that the chemical course for the student should be treated as a whole from the moment he enters the medical school to the time when he is dealing with chemical pathology in his final year. In the past this has certainly not been the case. In the university the chemistry and physical chemistry have been taught in the chemistry department, biochemistry has been taught by another group quite independent of the former, and the chemical pathology has been dealt with by an entirely separate department. Again, in most institutions, little or no attempt has been made to co-ordinate the work of these departments, with the result that a student may be taught to estimate chlorides in the inorganic chemical laboratory in his first year and may be taught an entirely different method of estimating chlorides in biological fluids in his second or third year, and is possibly given an entirely new method in the chemical pathology department. This segregation of the three periods of his chemical education leads to intellectual resentment on the part of the student, so that he almost takes pleasure in forgetting and refusing to apply what he has learned in the previous department.

Few would deny that those responsible for the teaching of the inorganic and physical chemistry should be sufficiently in touch with biology and the biological outlook to impress on the student that when, for example, he is conducting experiments on osmotic pressure in the inorganic chemical laboratory in the medical school or university, which seems to him so remote from the eagerly awaited ward or operating theatre, he is really actively preparing himself for this period. This making the student aware that his chemistry is being taught him for his own ultimate good, and that he should not regard it as a particularly unpleasant obstruction in an obstacle race, must run through the whole of the teaching of chemistry.

This question of the co-ordination of the various branches presents a difficult problem. One way to settle it would be to arrange for all the chemistry taught to the medical student to be under the control of one authority. This experiment is at present on trial at the Middlesex Hospital - Medical School, and has now been operating for three years. It is as yet too early to give any judgment on the practical results, as the scheme will obviously have to be in operation for at least six years in order that the finalyear students shall have been through the whole of the chemical course. The important point is that accurate co-ordination be obtained. Provided some scheme is put into force which ensures this, the teaching of chemistry to medical students is bound to improve.

\section{Choosing a Syllabus}

If this be accepted as the organization, we still have to face the further difficult task of choosing a syllabus. It is obvious that in the limited space at my disposal this important subject can be dealt with only in the most general terms. It would seem to me that the chemical education should be pyramidal in its construction-that is, the base should be extremely broad so that the student is grounded in the basic principles, and that as the teaching advances from inorganic and physical chemistry to organic chemistry the field can be narrowed as the pyramid rises.

Thus it is obviously important that a really sound knowledge of the physical chemistry of solutions, electrolytes, osmotic pressure, and colloid chemistry be given to the student. So far as is possible this should be treated in a non-mathematical manner. Many experts will object to this and say that it is impossible. After many years of teaching medical students, I have been impressed with the 
curious allergic objection that they have to any form of mathematics. This curious phenomenon is well known to all teachers, and one of the surest ways of alienating a class of medical students is to introduce some mathematical formula even of the simplest character. If enough trouble is taken by a sympathetic lecturer, this cardinal error can be avoided, and it is possible to explain to students the phenomena of physical and colloid chemistry without recourse to higher mathematics.

In the past one of the great difficulties in designing a course of chemistry for medical students has been the different types of school education. Thirty years ago the teachers in the first year might be faced with a group of students who varied between two extremes. At one end of the scale was the classically educated boy from one of the older public schools who knew no science at all, and at the other end the boy from the secondary school who could have passed his first M.B. in physics and chemistry the day he entered. From that time up to the present this difficulty has gradually become less and less, and to-day every studeni entering a medical school has at least some knowledge of physics and chemistry, and very often also of botany and zoology. At the present time, with the possibility of the abolition of the matriculation examination and the substitution of the new certificate of education, it is premature and impossible to say what will happen with regard to the preliminary education of the new entries. It is almost certain, however, that in the medical schools we can anticipate receiving students who have an increasing knowledge of the basic scientific subjects of physics, chemistry, and biology.

It is not the function of this article to discuss how much of the old first M.B. work should be done in school; the construction of the chemistry syllabus will therefore be based on the assumption that the student entering a medical school has an elementary general knowledge of inorganic and physical chemistry.

\section{Organic Chemistry}

The organic chemistry syllabus has always been one of the biggest bugbears of would-be reformers. The teacher of medical chemistry in a hospital medical school, in order to justify the importance of his subject, will try to make the syllabus as wide as possible, whilst the medical student in the university chemical department is often forced to attend lectures and practical classes on chemical subjects which he knows will never be of any interest to him. It would seem to me that we can profitably narrow this field of organic chemistry and restrict its teaching to those substances which are of importance in the body. These, by and large, will include proteins, fats, carbohydrates, purines, sterols, and pigments, and in order to understand the chemistry of such substances the student must know something of the basic aliphatic and aromatic compounds. This list is formidable enough, as anyone with knowledge would admit. There is obviously no point in teaching the medical student elaborate details of synihetic organic chemistry, nor is there any point in dragging him through a lot of dyestuff chemistry and similar fields so far removed from his own.

One of the most important errors to avoid is the feeling of satisfaction that some teachers and students get through memorizing formulae. This has always been one of the curses of medical chemical education. So many biological examiners experience a feeling of erudition when they can demand the writing of a formula for a steroid hormone from a student. It is most unfortunate that so many medi- cal students, and in fact many of their biological teachers also, feel they understand the whole sterol field because they can draw a cyclo-penteno-phenanthrene formula on the blackboard. What is much more important is that the student should realize that the fusion of a number of saturated six-membered rings gives rise to the possibility of innumerable stereo-isomers in this field, and that it is therefore possible to have a whole series of cortical steroids all with very similar formulae. In addition, the position of polar groups, such as methyl, hydroxyl, and ketonic, can modify the properties to such an extent that it is essential to have an idea of the importance of their positions in relation to configuration.

\section{Practical Teaching}

Up to the present I have dealt mainly with the theoretical side of the course in chemistry. Perhaps even greater difficulties are caused by the wide divergence of expert opinion on the question of practical teaching. Teachers can be divided into roughly two classes. There are those who maintain that the student can obtain valuable instruction by his making complicated quantitative estimations, and that even if the results are wide of the mark the fact that he has struggled through the determination will have demonstrated to him the principle of the method. The second group of teachers, to which I very definitely belong, maintain that this performance of elaborate experiments in determination, with the production frequently of ridiculous results, is not only useless but actively dangerous from an intellectual point of view. It encourages the development of the old bogy of the medical student already referred to - namely, that subjects like chemistry, etc., are put there as traps and obstacles to prevent him from getting on. The second group of teachers believe that the student should attempt experiments in quantitative determination only of a complexity that will enable him to practise them well enough to get accurate and reproducible results. The more complicated investigations can be shown in lecture demonstrations.

Many teachers seem to delude themselves into believing that medical students can perform accurate gas analyses with the Haldane apparatus and can do accurate blood analyses. Those of us who have had experience of running biochemical routine laboratories know the length of time it takes to train a technician in one or two blood or urine quantitative determinations. With an intelligent technician it requires weeks of training before one can rely on his results, and it is therefore most unfair to expect a medical student to master the more complicated determinations in the short time at his disposal.

Another important development in the modern teaching of chemistry to medical students is the very wholesome trend of employing biological material, and wherever possible human material, for experimental practical work. It is very obvious that if one can design experiments where the students examine the effect of some reaction on their own blood and urine they take much greater interest than if they are handed out some made-up solutions. The practical course in organic chemistry has been evolved in most schools and universities to contain exercises such as simple synthetic preparations which enable the student to understand the elementary principles of organic synthesis.

In biochemistry the same principle should hold, and the student should only do exercises which he can accomplish efficiently. Wherever possible the more complicated exercises should be illustrated by carefully thought-out lectures and demonstrations. 


\section{Chemical Pathology}

Finally, turning to chemical pathology, for the general course of practical instruction in examination of blood and urine from different types of cases it has always been found a good plan, if accommodation is available, for students to be able to carry out examinations on patients whom they are looking after in their medical and surgical appointments. While this tends to be a nuisance to those in charge of the laboratories, there can be no doubt that many biochemists of distinction to-day have entered the subject through this portal. In some institutions the students actually perform the routine investigations on the patients. In my experience this puts far too much strain on the students, and the results cannot be relied upon.

If the continuity of teaching is maintained, the student will appreciate it fully when he comes to his chemical pathology. If the scheme outlined has been properly implemented he will fall on the urinary steroidal examination in adrenogenital syndrome almost with relish and will start his studies of diabetes and other metabolic diseases with interest based on sound chemical knowledge. Another advantage of such co-ordination is that it enables the institution to provide interest for the teachers of inorganic and organic chemistry. If they are in the same department as the teachers of biochemistry and chemical pathology they do not lose sight of their students, and then they have the stimulus of research work in that they are in constant touch with biological material. This is very different from the old regime in medical schools where the teacher of inorganic and organic chemistry had no connexion whatsoever with those dealing with biochemistry and chemical pathology, being segregated in a separate department.

\section{Conclusion}

Anyone who attempts criticism of the medical curriculum or points out faults in the existing system of teaching exposes himself to a battery of criticism, and this applies doubly to the person who is rash enough to publish his article in a journal permitting correspondence. There is no doubt that many of those who read these brief notes will be tempted to write at once and say that these objections certainly do not apply to their particular university or medical school. I trust that those who are kind enough to study my remarks will understand that they are meant in an entirely general sense, and that there must be institutions where some or possibly all of the defects are avoided or minimized.

The Dutch have long realized the limitations of their own language as a medium for scientific expression. In the 17th century Leeuwenhoek was sending accounts of his discoveries to London for publication in English in the Philosophical Transactions, and as recently as 1947 English was chosen as the most suitable language for the series of abstracting journals published in Amsterdam under the title of Excerpta Medica. Dutch surgeons have now commenced publication in English of a new journal for their specialty, the Dutch Archives of Surgery (Archivum Chirurgicum Neerlandicum), which is sponsored by the Dutch College for the Advancement of Surgical Science. By this new journal surgeons in Holland hope to enjoy the advantages of international criticism and a broader interest in their work. Papers will be published in French or German also, but manuscripts submitted in Dutch will be translated into English. The journal will appear quarterly, at an annual subscription of $£ 22 \mathrm{~s}$. The agents in this country are Messrs. Baillière, Tindall and Cox.

\section{ON THE TEACHING OF BIOLOGY AS A PREPARATION FOR MEDICINE}

\author{
BY
}

\author{
F. A. E. CREW, M.D., F.R.C.P.Ed., F.R.S. \\ Professor of Public Health, University of Edinburgh
}

It is most unlikely that further discussion concerning this particular topic can yield conclusions significantly different from those presented in the 1948 Report of the B.M.A. Medical Curriculum Committee. Nevertheless it is perhaps desirable that such discussion should proceed, since in spite of the appearance of this most admirable report there is still much disputation and not a little misunderstanding both among medical students and among their teachers concerning the contribution which biology makes, or is expected to make, to the education of the future practitioner of medicine.

\section{Aims of the Curriculum}

The structure of the curriculum and the place of biology within it cannot be considered profitably until the aims of the curriculum are known. They certainly are not solely the production of the general practitioner, that lowest (or highest) form of professional life, the specialist in some particular branch (or twig) of medicine, or the medical scientist (physicist, chemist, anatomist, physiologist, pathologist, bacteriologist, biochemist, pharmacologist, and the like). There would seem to be a general though occasionally hesitant agreement that the product is meant to be a person who, in virtue of his initial organic endowment and early upbringing and as the result of his exposure to this curriculum, has become fitted to pursue further study and thus ultimately equip himself with that constellation of qualities, personal, social, and professional, that is necessary for the kind of work he proposes to do and for the kind of life he proposes to lead. Graduation is thus the starting-point for a career in one of the three major provinces of medicine. The graduate can proceed thence to become a medical scientist whose hope is to advance knowledge in a particular field of medical science, a specialist in medical practice dealing with some particular part of a human being in relation to the rest of him (for example, an ophthalmologist ; a specialist in the utilization of some particular technique demanding a mastery over some particular complicated machinery and of value in diagnosis and therapy-e.g., radiology ; a specialist in some particular field of medicine-e.g., public health), or a generalist in medical practice concerning himself with the total individual in relation to his total external physical and social world.

So far as the future practitioner of medicine is concerned, the aim of medical education is to produce out of an individual with the appropriate personality, aptitudes, and inclinations an educated person. He must be fitted to claim his proper place in the society of which he is a co-operative member and be equipped with the special outlook, knowledge, and skills which will enable him to render service of a special and expert kind to the community; this service taking two main forms - the skilful application of his special abilities to the immediate task of conserving, augmenting, and restoring the health, happiness, and efficiency of individuals or of a community, and the expansion of the special corpus of knowledge which is medicine by additions thereto gleaned from his own activities and experience. 